\title{
Survey on ethnobotanical uses of anti-cancer herbs in Southern region of llam, West Iran
}

\author{
Mahmoud Bahmani, ${ }^{1}$ Amir Sasan Mozaffari Nejad, ${ }^{2}$ Naseer Ali Shah, ${ }^{3}$ Sayed Afzal Shah, ${ }^{4}$ \\ Mahmoud Rafieian-Kopaei, ${ }^{5}$ Leila Mahmoodnia ${ }^{6}$ \\ ${ }^{1}$ Biotechnology and Medicinal Plants Research Center, Ilam University of Medical Sciences, Ilam; ${ }^{2}$ Nutrition Health \\ Research Center, Hamadan University of Medical Sciences, Hamadan, Iran; ${ }^{3}$ Deartment of Biosciences, COMSATS \\ Institute of Information Technology, Islamabad; ${ }^{4}$ Department of Plant Sciences, Faculty of Biological Sciences, \\ Quaid-i-Azam University Islamabad, Pakistan; ${ }^{5}$ Medical Plants Research Center, Basic Health Sciences Institute, \\ Shahrekord University of Medical Sciences, Shahrekord; ' ${ }^{6}$ Department of Internal Medicine, Shahrekord University of \\ Medical Sciences, Shahrekord, Iran
}

\begin{abstract}
One of the most common problems in the medical world is the resistance of cancer cells to anti-tumor drugs, so finding new anticancer agents with minimal side effect is essential. This study aims at identifying medicinal plants in to the southern region of Ilam province in west Iran, which are traditionally used in the treatment of cancer by herbal practitioners. This study was conducted in the southern district of Ilam province, Iran. The study was conducted from August 2013 to October 2014 by using questionnaire and interview from herbal practitioners. The collected data were analyzed through relative frequency of citation index (RFC). In this study, 36 herbal practitioners were interviewed. A sum of 21 medicinal plants used in variety of cancers from 16 families were identified for the Southern District of Ilam. Asteraceae was the dominant plant family, and the most used organ was aerial parts (44\%). Dermal cancer was the most treated cancer by herbal practitioners in the region with different herbs. Lawsonia inermis and Satureja khuzistanica were the most cited species for anti-
\end{abstract}

Correspondence: Mahmoud Rafieian-Kopaei, Medical Plants Research Center, Basic Health Sciences Institute, Shahrekord University of Medical Sciences, Shahrekord, Iran.

E-mail: rafieian@yahoo.com

Key words: Ethnobotany; Medicinal plants; Cancer; Ilam; Iran.

Acknowledgements: this work was done by support of Research Deputy of Shahrekord University of Medical Sciences, Shahrekord, Iran.

Received for publication: 16 April 2016.

Revision received: 23 January 2017.

Accepted for publication: 9 February 2017.

(C) Copyright M. Bahmani et al., 2017

Licensee PAGEPress, Italy

Journal of Biological Research 2017; 90:5939

doi:10.4081/jbr.2017.5939

This article is distributed under the terms of the Creative Commons Attribution Noncommercial License (by-nc 4.0) which permits any noncommercial use, distribution, and reproduction in any medium, provided the original author(s) and source are credited. cancer use. On comparison with the literature it was revealed that $61.9 \%$ plants are not scientifically validated against any type of cancer. New therapeutic remedies were reported for the first time and a number of similar effects of the reported plants were found in other studies. As a result of the present study we recommend the plants documented in the present study, which are not pharmacologically assessed, for further pharmacological studies.

\section{Introduction}

In the last 20 years, cancer has become one of the leading causes of human death. According to the America Cancer Society report, 7.6 million people died in 2007 due to cancer. ${ }^{1}$ Cancer involves multistage alterations in genetic makeup of the normal cells provoked by carcinogens or by the mismanagement of DNA repairs system of the cell. ${ }^{2}$

A flurry of research data demonstrated the intense need to develop new strategies against these cancers and to investigate potential naturally derived candidates with capability to halt these modifications ultimately stop carcinogenesis. In this consent a number of published data evidenced the positive prospective of the plant extracts and their derived compounds as anticarcinogenic agents with cancer chemopreventive characteristics. Many diversified lines of research evidenced that plants are very potent mediators for the management of cancerous malaises owing to the efficacy of the approved anticancer drugs which were plant oriented e.g. Taxol from Taxus brevifolia; vinblastine and vincristine from Catharanthus roseus. ${ }^{3,4}$

The use of medicinal plants has long been popular among Iranians. The thousand years old medical history has mentioned the use of medicinal plants fundamental and comprehensive to solutions of different ailments. The use of these guidelines can be suitable for resolving some of the health problems of the community. ${ }^{5-8}$ The use of natural products for medical purposes has been in practice since thousands of years and is known in Iran as Iranian traditional medicine and physicians have worked a lot in this direction. 5,6,9,10 An analysis of new and approved drugs for cancer by the United States Food and Drug Administration over the period of 1981-2002 showed that $62 \%$ of these cancer drugs were of natural origin. ${ }^{11}$

Ilam province is known for its rich flora diversity. It has about 1000 species, among which 400 plants are reported for medicinal purposes. ${ }^{12}$ Considering the rich flora of this province, the current study was carried out to identify and document medicinal plants 
used as anti-cancer. Many traditional healers and herbalists in the Ilam province of Iran have been treating cancer patients for many years using various medicinal plant species. Despite the long history of cancer treatment using herbal remedies in the Province, the knowledge and experience of these herbalists have not been scientifically documented.

Therefore, this study aims at identifying medicinal plants in to the southern region of Ilam province in west Iran, which are traditionally used in the treatment of cancer by herbal practitioners.

\section{Materials and methods}

\section{Study area}

Ilam province is one of the western provinces of Iran and is located in the mountainous and semi-warm area. The capital of the province is Ilam city. Ilam province is neighbor from west with Iraq, from south with Khuzestan province, from east with Lorestan province and from north with Kermanshah province. Prior to Rezashah period, this area was called Poshtkoh Lorestan. Kurd tribe is main resident of Ilam city. Kurdish is main speaking language of Ilam residents. A common Kurdish dialect in Ilam province is Ilami Kurdish and the second common spoken dialect is Lori and Laki and are scattered across the area. Ilami Kurdish is also called Fili. Kurdish is common in most areas of the region.

\section{Topography and climate}

Ilam province especially Ilam city, known as the thyme land and the rising sun land, is located in west of Iran. The Geographical location of the province is visible in Figure 1.

Geologically, the lowland plain and hills of the province are composed mostly of gypsum and calcareous soils, and the mountainous parts are composed mostly of calcareous, sandstone or con- glomerate materials supporting fertile agricultural soils. Ilam city is located at altitude $33^{\circ} 38^{\prime}$ north and longitude at $46^{\circ} 26^{\prime}$ east. The highest mountains of the province are Kabir kuh (Kanseifi climax) which stretches from the north-west to the south-east between the lowland and the mountainous parts of the province and reach a height of $2790 \mathrm{~m}$. Gachan, Manesht, Ghalarang and Reno around Ilam city is a continuation of the Zagros mountains and the lowlands are a continuation of the Mesopotamian plains which have a warm and frost-free climate. A big part of the province is more or less a semi-arid region, and other parts have a temperate climate and a very short period of winter frost. The average annual precipitation of Ilam city is about $500 \mathrm{~mm}$ (https://en.wikipedia.org/wiki/Ilam_Province)

\section{Data collection}

This ethnobotanical survey of Ilam was conducted during August 2013 to October 2014. The data of native herbal plants were collected from 36 traditional physicians and grocers. The informants were between the 35 to 67 years age. The information was collected through questionnaire, interviews and discussions in their local language (Kurdish).

A semi-structured questionnaire was used to extract information on types of ailments treated by the use of medicinal plants and plant parts used in treating different type of cancers. The interviews were conducted with prior consent from all the informants following the ethical code of the international society of ethnobiology. The herbal practitioners were asked to provide information about each local medicinal plant, vernacular name, uses (particularly medicinal uses), route of administration and plant part used for treating cancer.

All the ethnobiologically important plants were collected from the area and pressed, dried, labeled and mounted on herbarium sheets and preserved in the Natural Resources Research Center Ilam Province, Ilam, Iran. Plant sample identity was confirmed from the flora of Iran.

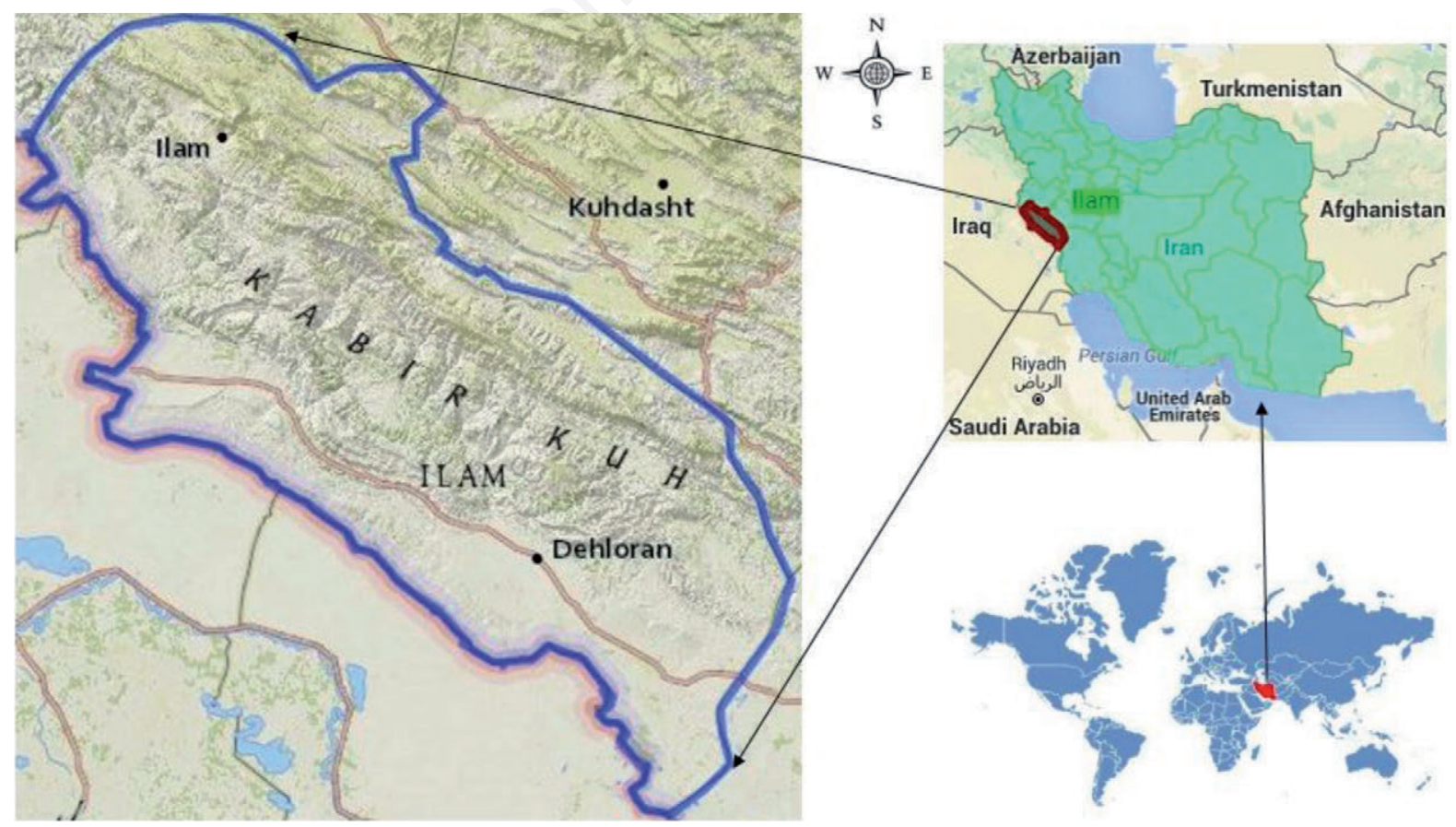

Figure 1. Geographical location of Southern Region of Ilam, West Iran. 


\section{Data analysis}

Conversion of the qualitative data into quantitative data is essential for hypothetical testing, statistical validation and comparative analysis. Quantitative information increases the probability of identifying the promising pharmacological important plant. ${ }^{13}$

Data were entered into MS Excel and were quantitatively analyzed using Relative Frequency Citation (RFC). RFC shows the local importance of each species and is calculated from the frequency of citation (FC, the number of informants mentioning the usage of the species) divided by the total number of informants in the survey $(\mathrm{N})$. RFC values can be defined by following formula: $\mathrm{RFC}=\mathrm{FC} / \mathrm{N}$ (RFC values ranges from zero to one).

\section{Results and Discussion}

In the result of present survey, 21 anti-cancer plants in the southern area of Ilam province were identified shown in Table 1. The number of plant families, the percentage of plant organs and the percentage of each type of cancer treatment are illustrated in Figures 2-4. Plants reported in this study belong to 16 different families. The most frequently used plant family for cancer therapy was Asteraceae reporting tree species as illustrated in Figure 2.

These findings are not in agreement with, ${ }^{22}$ who reported Euphorbiaceae as major family for anticancerous plants. Majority of the plant species were reported to be used for dermal cancer fol-

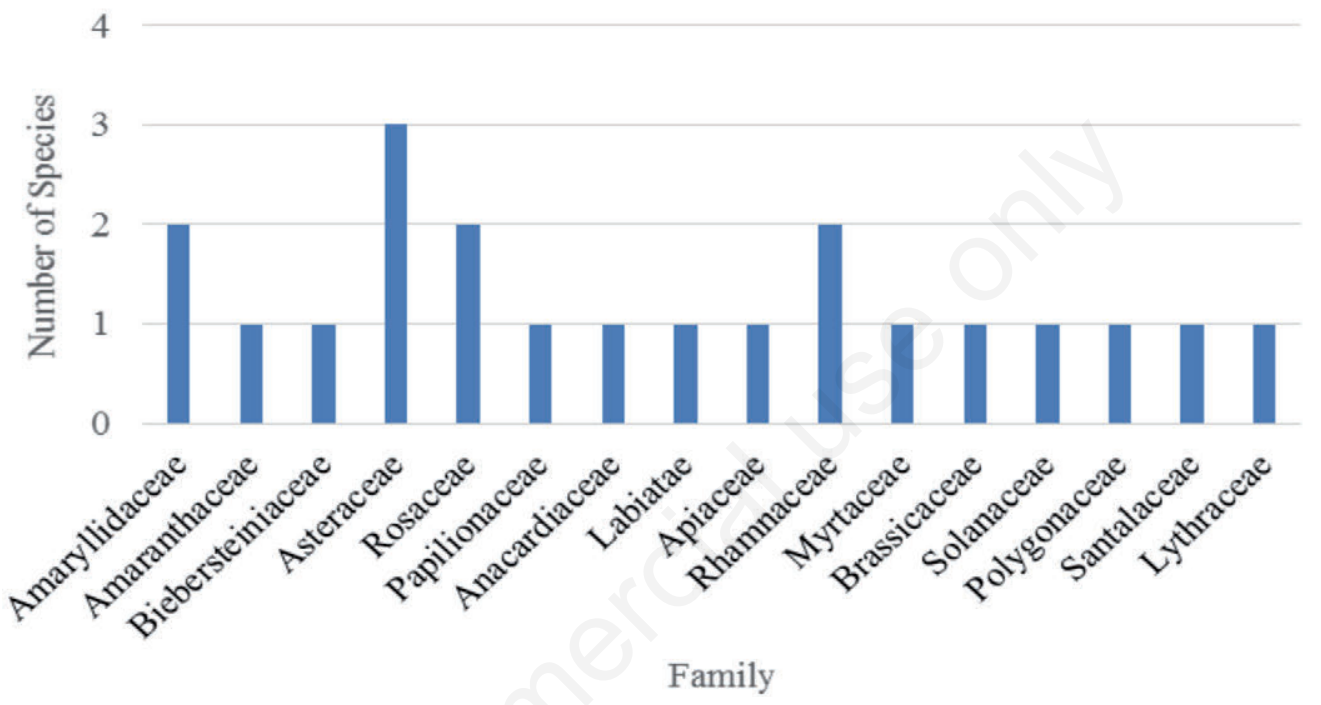

Figure 2. Number of anti-cancer plant families.

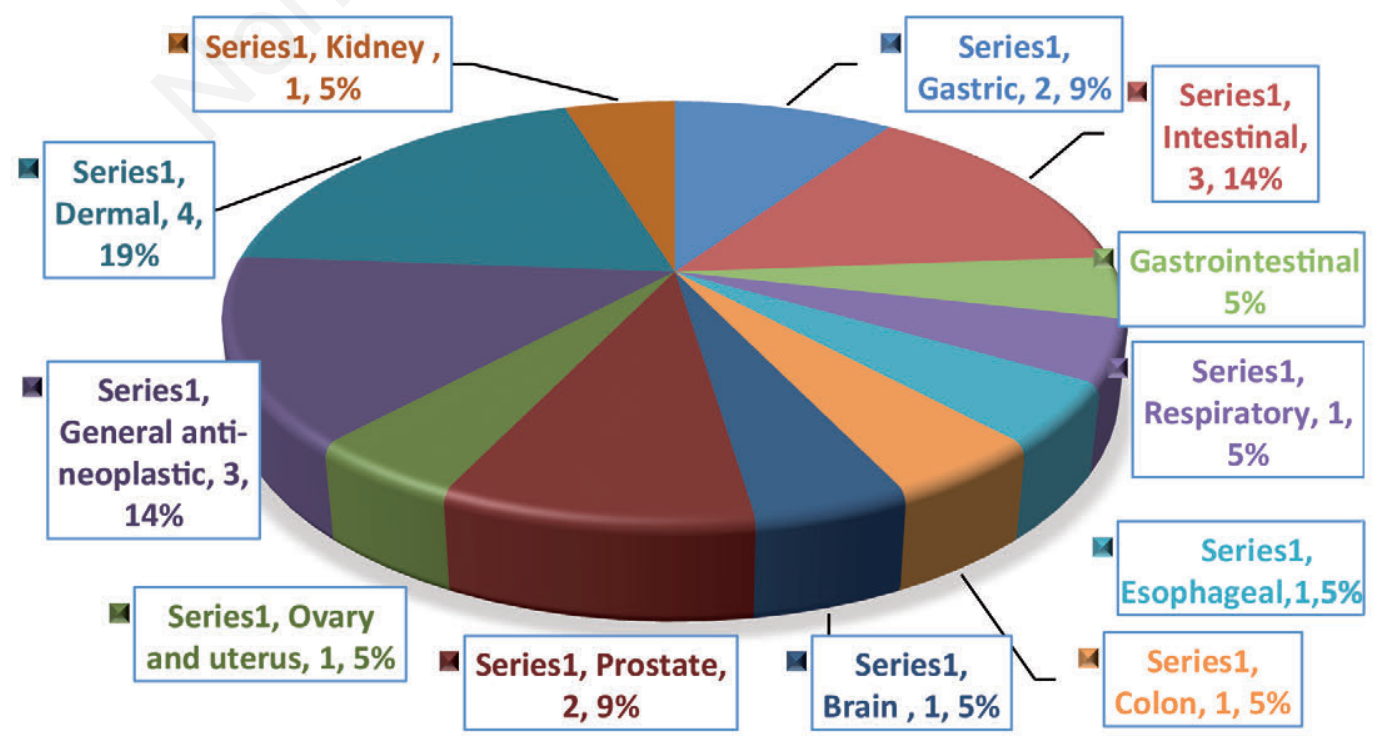

Figure 3. Percent of medicinal plants used for various the types' of cancer. 


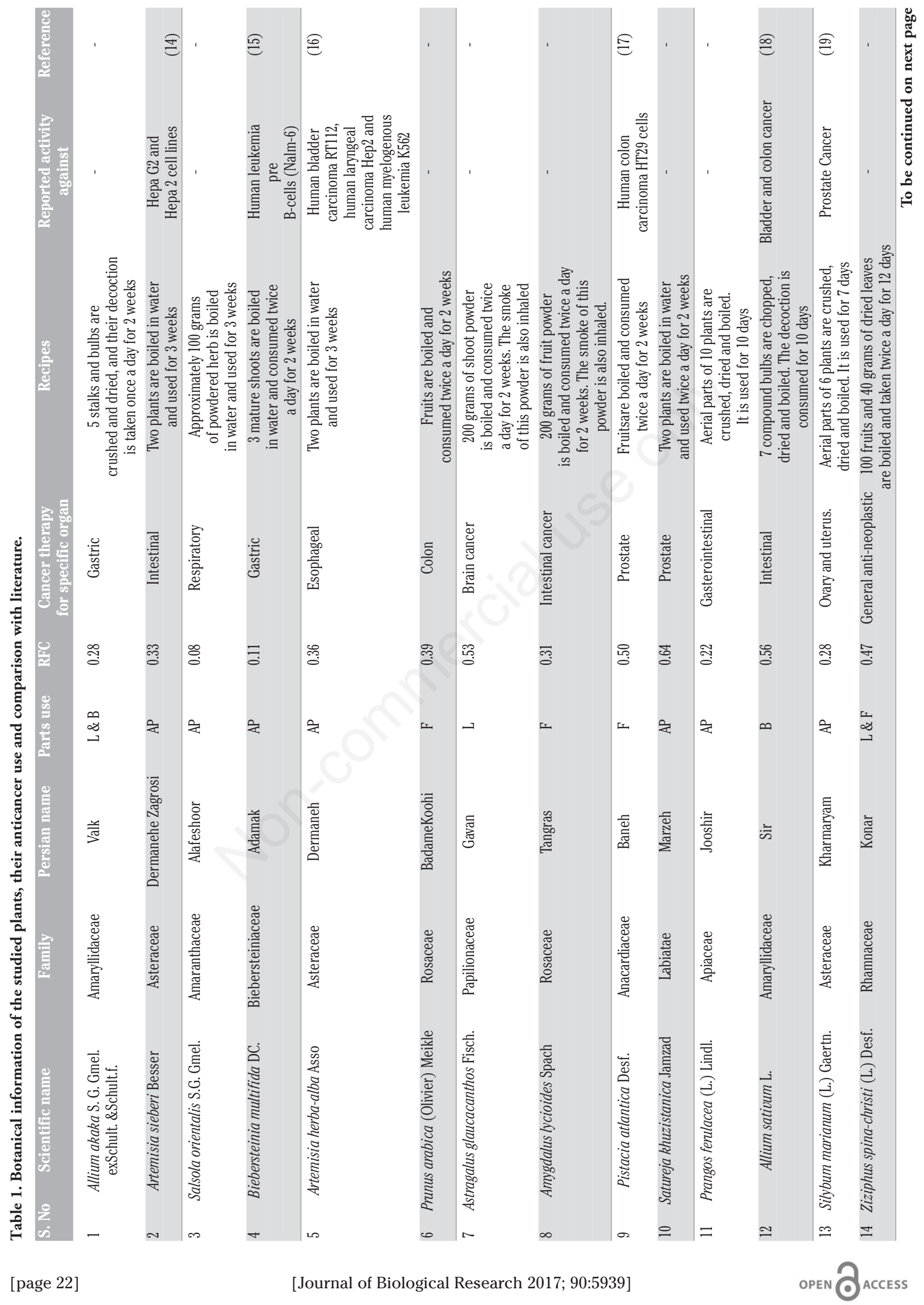




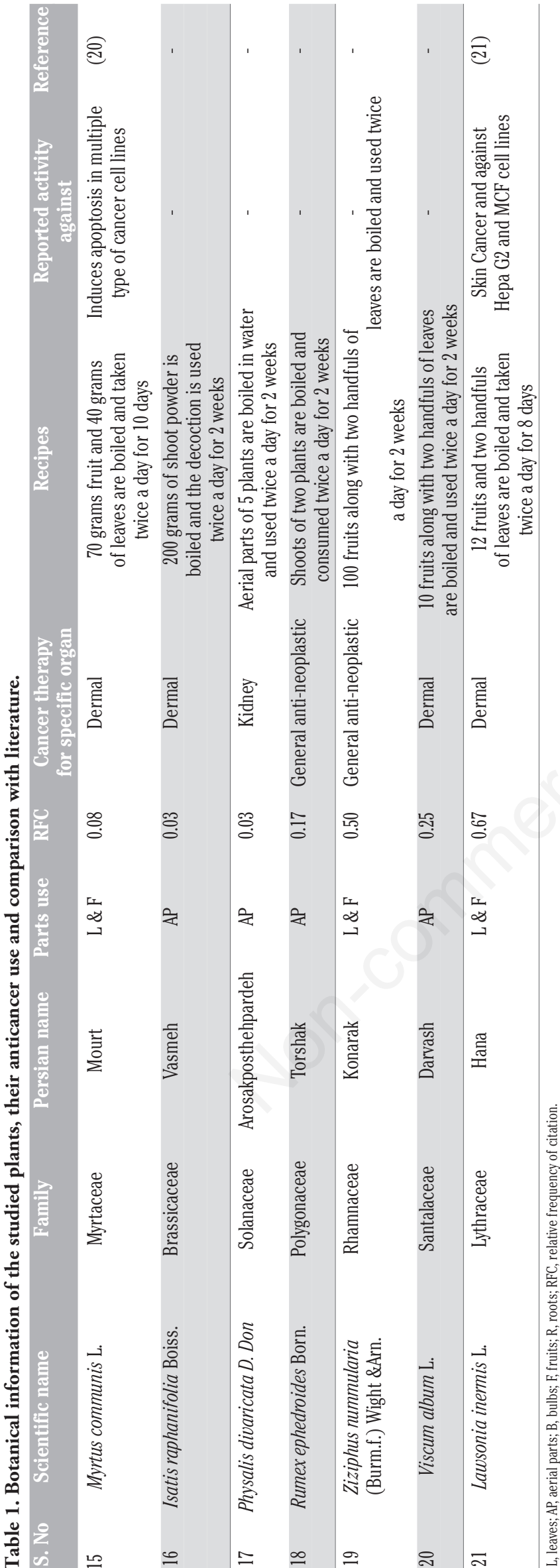

lowed by category of plants reported as general antineoplastic as shown in Figure 3.

According to the results, aerial parts of the plants (44\%) were the most frequently used plant part while roots, bulb and flower were the lowest one as shown in Figure 4. Lawsonia inermis was the most cited plant $(\mathrm{RFC}=0.67)$ as anticancer followed by Satureja khuzistanica $(\mathrm{RFC}=0.64)($ Table 1$)$.

Searching literature for scientific validation of reported plants, it was observed that only $38.1 \%$ of plants were investigated in in-vitro or in-vivo model for their anticancer activity. Comparing to the published literature it was observed that scientifically it was investigated in different type of organ cell line against our report except $L$. inermis. So there is a need to investigate the plant extracts in cell lines of the organ what is reported here in our study. Among all the plants L. inermis was the most evaluated plant for anticancer activity; Raja, ${ }^{23}$ demonstrated that aqueous leaf extract of $L$. inermis possesses strong antitumor activity in both DMBA-induced 2-stage skin carcinogenesis and B16F10 melanoma tumour models in mice.

In addition to this study, its anticancer activity is also reported in other type of cells such as Ehrlich ascites carcinoma cells; ${ }^{24}$ human colon cancer (Caco-2) and liver cancer (HepG2) cell lines $^{25,26}$ and human leukaemia cell-line HL60. ${ }^{27}$ The other survey by Rahmat, ${ }^{28}$ reported that essential oil isolated from the leaves have strong cytotoxic activity against liver cell lines (HepG2). Also, a study by Ali and Grever, ${ }^{29}$ demonstrated that iso plumbagin, isolated from the stem bark of $L$. inermis, displays cytotoxicity towards melanoma and colon cancer cell lines, as well as against several non-small cell lung, colon, CNS and renal cell lines. Ethanolic extract of Artemisia sieberi was investigated by Emami, ${ }^{14}$ against different type of cancer cell lines and found it active against these cells, but in our study area it has been reported against intestinal cancer. Therefore, it should be investigated against intestinal cancer and bioactive constituents may be isolated in pure form for mechanism of anticancer activity.

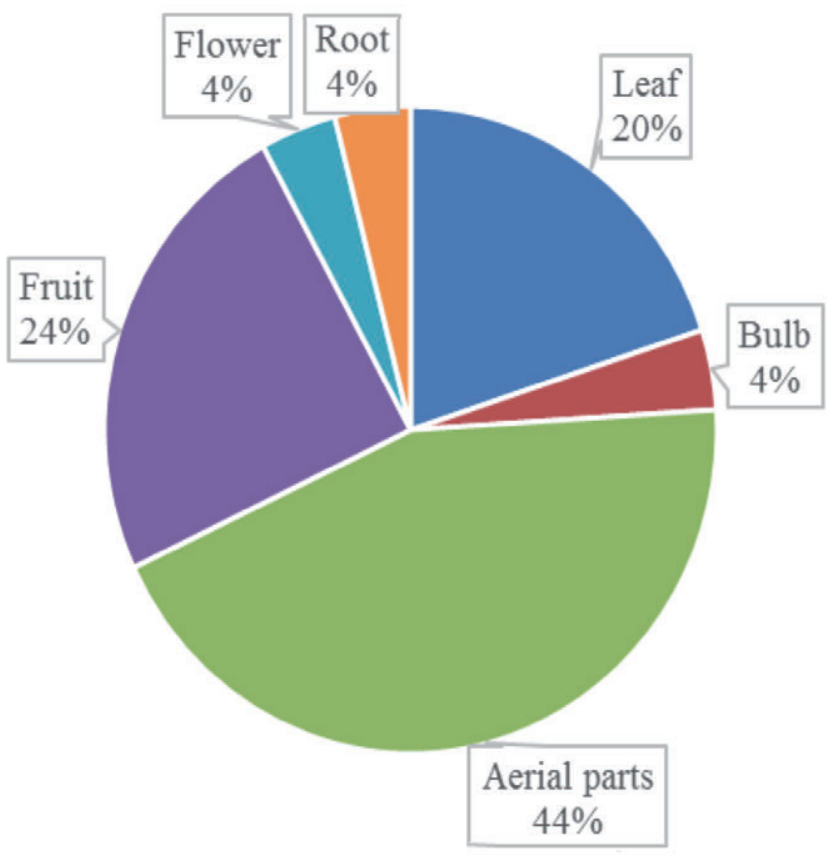

Figure 4. Percent of plant parts used. 
The previous study by Dabaghian, ${ }^{15}$ evaluated antimutagenisty and anticancer assay of ethanol extract of B. multifida and found it active. Artemisia herba-alba extract showed a high anticancer activity against several cell lines (human bladder carcinoma RT112, human laryngeal carcinoma Hep2 and human myelogenous leukemia K562 with IC50 = 81.59 $\pm 4.4,59.05 \pm 3.66$ and $90.96 \mathrm{mg} / \mathrm{L}$ respectively and correlated it with phenolic contents. ${ }^{16}$ Pistacia atlantica methanolic extract has shown significant cytotoxic effects against human colon carcinoma HT29 cells. ${ }^{17}$ In an effort to develop improved treatments for bladder cancer, the results of Lamm and Riggs, ${ }^{18}$ revealed that $A$. sativum extract is effective in the MBT2 murine bladder tumor model. Hence, A. sativum is potentially an effective therapy for bladder cancer, and clinical trials should be considered. Extracts from the seeds of milk thistle, Silybum marianum, are known commonly as silibinin and silymarin and possess anticancer actions on human prostate carcinoma in vitro and in vivo. Seven distinct flavonolignan compounds and a flavonoid have been isolated from commercial silymarin extracts. Most notably, two pairs of diastereomers, silybin A and silybin B and isosilybin A and isosilybin $\mathrm{B}$, are among these compounds.

Findings are suggestive that extracts enriched for isosilybin B, or isosilybin B alone, might possess improved potency in prostate cancer prevention and treatment. ${ }^{19}$ In a study conducted by Tretiakova, ${ }^{20}$ on the anticancer activity of myrtucommulone isolated from M. communis, it was found that it could induce apoptosis in cancer cells via the mitochondrial pathway involving caspase-9. The large number of plant species has not been analyzed for their antitumor potential $(61.9 \%)$ or have only been studied in extract form, indicates there is ample space in the field for future investigations of the anticancer activity of such plants in Iran.

In general, the plants that were used in various experimental studies showed significant results in the pharmacological models used, and these results corroborated their popular use. Many researchers selected plants used in alternative and complementary medicine to treat cancer, with the goal of evaluating the antitumor activity. Satisfactory results has been found for both in-vitro and in-vivo activities. ${ }^{30,31}$ Medicinal herbs has the bioactive phytochemicals that are used as therapeutic agents. So, the researchers demonstrated that plant species used in folk medicine are a promising source for anticancer effects and also, new molecules. ${ }^{32-40}$

\section{Conclusions}

In the present study it is suggested that activity of plant species should be investigated against different cancer cell lines especially of the reported organ and those plants which are studied at extract level should be further processed by bioassay guided isolation procedure to isolate bioactive constituent in pure form. The isolation, identification of active principles and pharmacological studies of the active phyto-constituents may be considered and studied elaborately to treat effectively for various types of cancer.

\section{References}

1. Thun MJ, DeLancey JO, Center MM, et al. The global burden of cancer: priorities for prevention. Carcinogenesis 2010;31:100-10.

2. Luqman S, Pezzuto JM. NFאB: a promising target for natural products in cancer chemoprevention. Phytother Res 2010;24: 949-63.
3. Gupta MM, Singh DV, Tripathi AK, et al. Simultaneous determination of vincristine, vinblastine, catharanthine, and vindoline in leaves of Catharanthus roseus by high-performance liquid chromatography. J Chromatogr Sci 2005;43:450-3.

4. Wall ME, Wani MC. Camptothecin and taxol: discovery to clinic-thirteenth Bruce F. Cain Memorial Award Lecture. Cancer Res 1995;55:753-60.

5. Mozaffari Nejad AS, Kamkar A, Giri A, et al. Ethnobotany and folk medicinal uses of major trees and shrubs in Northern Iran. J Med Plants Res 2013;7:284-9.

6. Mozaffari Nejad AS, Bayat M, Ahmadi AA. Investigation of aflatoxin B1 in spices marketed in Hyderabad, India using ELISA method. J Pure Appl Microbio 2013;7:3219-23.

7. Bahmani M, Zargaran A, Rafieian-Kopaei M, et al. Ethnobotanical study of medicinal plants used in the management of diabetes mellitus in the Urmia, Northwest Iran. Asian Pac J Trop Med 2014;7:348-54.

8. Bahmani M, Golshahi H, Mohsenzadegan A, et al. Comparative assessment of the anti- Limnatis nilotica activities of Zingiber officinale methanolic extract with levamisole. Comp Clin Pathol 2013;22:667-70.

9. Jalali H, Mozaffari Nejad AS, Ebadi AG, et al. Ethnobotany and folk pharmaceutical properties of major trees or shrubs in Northeast of Iran. Asian J Chem 2009;21:5632-8.

10. Asadbeigi M, Mohammadi T, Rafieian-Kopaei $M$, et al. Traditional effects of medicinal plants in the treatment of respiratory diseases and disorders: an ethnobotanical study in the Urmia. Asian Pac J Trop Med 2014;7:364-8.

11. Gonzales GF, Valerio LG Jr. Medicinal plants from Peru: a review of plants as potential agents against cancer. Anticancer Agents Med Chem 2006;6:429-44.

12. Bahmani M, Eftekhari Z. An ethnoveterinary study of medicinal plants in treatment of diseases and syndromes of herd dog in southern regions of Ilam province, Iran. Comp Clin Path 2012; 22: 403-7.

13. Ibrar M, Rauf A, Hadda TB, et al. Quantitativeethnobotanical survey of medicinal flora thriving in Malakand Pass Hills, Khyber Pakhtunkhwa, Pakistan. J Ethanopharmacol 2015;169: 335-46.

14. de Melo JG, Santos AG, de Amorim EL, et al. Medicinal plants used as antitumor agents in Brazil: an ethnobotanical approach. Evid Based Complement Alternat Med 2011;2011: 365359.

15. Raja W, Agrawal RC, Ovais M. Chemopreventive action of Lawsonia inermis leaf extract on DMBA-induced skin papilloma and B16F10 melanoma tumour. Pharmacologyonline 2009;2:1243-9.

16. Ozaslan M, Zumrutdal ME, Daglioglu K, et al. Antitumoral effect of $L$. inermis in mice with EAC. Int $\mathrm{J}$ Pharmacol 2009;5:263-7.

17. Endrini S, Rahmat A, Ismail $P$, et al. Comparing of the cytotoxicity properties and mechanism of Lawsonia inermis and Strobilanthes crispus extract against several cancer cell lines. J Med Sci 2007;7:1098-102.

18. Kumar M, Kumar S, Kaur S. Identification of polyphenols in leaf extracts of Lawsonia inermis L. with antioxidant, antigenotoxic and antiproliferative potential. Int $\mathrm{J}$ Green Pharm 2014;8:23-36.

19. Ong CY, Ling SK, Ali RM, et al. Systematic analysis of in vitro photo-cytotoxic activity in extracts from terrestrial plants in Peninsula Malaysia for photodynamic therapy. J Photochem Photobiol B 2009;96:216-22.

20. Rahmat A, Edrini S, Ismail P, et al. Chemical constituents, 
antioxidant activity and cytotoxic effects of essential oil from Strobilanthes crispus and Lawsonia inermis. J Biol Sci 2006;6:1005-10.

21. Ali M, Grever M. A cytotoxic naphthoquinone from Lawsonia inermis. Fitoterapia 1998;69:181-3.

22. Emami SA, Vahdati-Mashhadian N, Vosough R, et al. The anticancer activity of five species of Artemisia on Hep2 and HepG2 cell lines. Pharmacologyonline 2009;3:327-39.

23. Dabaghian FH, Entezari M, Ghobadi A, et al. Antimutagenicity and anticancer effects of Biebersteinia multifida DC. Ann Res Rev Biol 2014;4:906-13.

24. Khlifi D, Sghaier RM, Amouri S, et al. Composition and antioxidant, anti-cancer and anti-inflammatory activities of Artemisia herba-alba, Ruta chalpensis L. and Peganum harmala L. Food Chem Toxicol 2013;55:202-8.

25. Rezaei PF, Fouladdel S, Hassani S, et al. Induction of apoptosis and cell cycle arrest by pericarp polyphenol-rich extract of Baneh in human colon carcinoma HT29 cells. Food Chem Toxicol 2012;50:1054-9.

26. Lamm DL, Riggs DR. The potential application of Allium sativum (garlic) for the treatment of bladder cancer. Urol Clin North Am 2000;27:157-62.

27. Davis-Searles PR, Nakanishi Y, Kim NC, et al. Milk thistle and prostate cancer: differential effects of pure flavonolignans from Silybum marianum on antiproliferative end points in human prostate carcinoma cells. Cancer Res 2005;65:4448-57.

28. Tretiakova I, Blaesius D, Maxia L, et al. Myrtucommulone from Myrtus communis induces apoptosis in cancer cells via the mitochondrial pathway involving caspase-9. Apoptosis 2008;13:119-31.

29. Kapadia GJ, Rao GS, Sridhar R, et al. Chemoprevention of skin cancer: effect of Lawsonia inermis L. (Henna) leaf powder and its pigment artifact, lawsone in the Epstein-Barr virus early antigen activation assay and in two-stage mouse skin carcinogenesis models. Anticancer Agents Med Chem 2013;13: 1500-7.

30. Tayarani-Najaran Z, Emami SA, Asili J, et al. Analyzing cyto- toxic and apoptogenic properties of Scutellaria litwinowii root extract on cancer cell lines. Evid Based Complement Alternat Med 2011;2011:1-9.

31. Matsuda T, Maekawa K, Asano K, et al. Suppressive effect of Juzen-Taiho-To on lung metastasis of B16 melanoma cells in vivo. Evid Based Complement Alternat Med 2011;2011:1-5.

32. Mozaffari Nejad AS, Shabani S, Bayat M, et al. Antibacterial effect of garlic aqueous extract on Staphylococcus aureuses in hamburger. Jundishapur J Microb 2014;7:1-5.

33. Eslami M, Bayat M, Mozaffari Nejad AS, et al. Effect of polymer/nanosilver composite packaging on long-term microbiological status of Iranian saffron (Crocus sativus L.). Saudi J Biol Sci 2016;23:341-7.

34. Ebrahimie M, Bahmani M, Shirzad H, et al. A review study on the effect of Iranian herbal medicines on opioid withdrawal syndrome. J Evid Based Complem Altern Med 2015;20:302-9.

35. Eftekhari Z, Bahmani M, Mohsenzadegan A, et al. Evaluating the anti-leech (Limnatis nilotica) activity of methanolic extract of Allium sativum L. compared with levamisole and metronidazole. Comp Clin Path 2012; 21:1219-22.

36. Kamkar A, Shamse Ardekani MR, Shariatifar N, et al. Antioxidative effect of Iranian Pulicaria gnaphalodes extracts in soybean oil. S Afr J Bot 2013;85:39-43.

37. Bahmani M, Banihabib E. Comparative assessment of the antiAnnelida (Limnatis nilotica) activity of nicotine with niclosamide. Global Vet 2013;10:153-7.

38. Bahmani M, Mirhoseini M, Shirzad H, et al. A review on promising natural agents effective on hyperlipidemia. J Evid Based Complementary Altern Med 2015;20:228-38.

39. Bahmani M, Shirzad H, Mirhosseini M, et al. A review on ethnobotanical and therapeutic uses of fenugreek (Trigonella foenum-graceum L). J Evid Based Complem Altern Med 2016; 21:53-62.

40. Asadi-Samani M, Rafieian-Kopaei M, Azimi N. Gundelia: a systematic review of medicinal and molecular perspective. Pak J Biol Sci 2013;16:1238-47. 